\title{
Newly Developed Major Neurological Injury After Open Heart Surgery
}

Etik Kurul Onayı: Hastane Yerel Etik Kurul onayı alınmıştır (Tarih 29.05.2018, No: 41) Çıkar Çatışması: Bu makalenin yazarı ve/veya yayınlanması ile ilgili çıkar çatısması voktur.

Finansal Destek: Yazarlar bu makalenin araștırma ve/veya yazarlığı için herhangi bir maddı destek almamışlardır.

Hasta Onamı: Retrospektif bir çalışma olduğu için hasta onamı alınmamıştır.
Ethics Committee Approval: Hospital local ethics committee approved (date: 29.05.2018, no: 41)

Conflict of Interest: No conflicts of interest with respect to the authorship and/or publication of this article.

Funding: The authors received no financial support for the research and/or authorship of this article. Informed Consent: No patient consent was obtained because it was a retrospective study.

Cite as: Gökbulut Bektaş Ş, Altınkaya Çavuş M, Demir A. Açık kalp cerrahisi sonrasında yeni gelişen majör nörolojik hasarlanma, GKDA Derg. 2019;25(2):113-8.

\section{Öz}

Amaç: Nörolojik hasarlanma kalp cerrahisinin en ciddi komplikasyonlarından biridir. Bu yazıda açık kalp cerrahisi yapılan merkezimizde son 2 yılda postoperatif tip 1 nörolojik hasar gelişmiş hastaları değerlendirmeyi amaçladık.

Yöntem: Hastanemizde son 2 yılda 2689 hastanın açık kalp cerrahisi geçirdiği saptandı. Bunların içinde postoperatif dönemde aşikar nörolojik hasar gelişen 50 hasta belirlendi. Bu hastaların verilerine elektronik veri tabanından ve arssivden dosya taraması yapılarak ulaşıldı.

Bulgular: Verilerine ulaşılan 50 hasta değerlendirildi. Hastaların yaş ortalaması $60.4 \pm 10.2$ yıl olarak bulundu. Hastaların \%61.2'sine hipertansiyon, \%22.4'üne diyabet eşlik etmekteydi. Hastalara uygulanan prosedürler sıklık sırasına göre \%54 koroner baypas cerrahisi, \%20 çoklu cerrahi prosedürler ve \%14 aort cerrahisiydi. Ortalama KPB süresi $131.1 \pm 58.6$ dk. idi. Buna göre serebrovasküler olay etiyolojisinde \%90 oranında embolinin neden olduğu iskemik inme gözlenirken, \%10 hastada hipoperfüzyona bağıı inme görülmüștür. SVO sonrası kalıcı hasar \%56 hastada bulundu. Mortalite ise 17 hastada (\%34) mevcuttu.

Sonuç: Araştırma sonucunda, hastanemizde açık kalp cerrahisi sonrasında aşikar nörolojik hasarlanma oranı \%1.9 bulundu. Literatürde bununla ilgili olarak \%0.5-5.4 gibi geniş bir aralık verilmiştir. Hastalarımızdaki nörolojik hasarlanmanın etiyolojisinde daha çok intraoperatif embolik faktörlerin yer aldığını düşünmekteyiz.

Anahtar kelimeler: postoperatif inme, kardiyak anestezi, postoperatif nörolojik komplikasyon, postoperatif morbidite, postoperatif mortalite, serebrovasküler olay

\section{ABSTRACT}

Objective: Neurological injury is one of the most serious complications of cardiac surgery. In this study, we aimed to evaluate patients who had postoperative type 1 neurological injury after open heart surgery within the last two years in our center.

Method: In our hospital, 2689 patients underwent open heart surgery in the last two years Among them 50 patients with obvious neurological damage were detected during postoperative period. The data of these patients were obtained by screening electronic database and archive files.

Results: Fifty patients with accessible data were evaluated. The mean age of the patients was $60,4 \pm 10,2$ years. While $61,2 \%$ of the patients had concomitant hypertension and $22,4 \%$ of them had also diabetes. Procedures applied to the patients in order of decreasing frequency were coronary bypass surgery (54\%), multiple surgical procedures (20\%) and aortic surgery (14\%). The mean duration of CPB was 131,1 $\pm 58,6$ min. Accordingly, as etiologies of cerebrovascular event, ischemic stroke caused by emboli was observed in $90 \%$, and hypoperfusion- related stroke in $10 \%$ of the patients. Permanent damage after CVE occurred in 56\% of patients. Mortality was observed in 17 patients (34\%).

Conclusion: In our study, the rate of obvious neurological injury after open heart surgery was $1,9 \%$ in our hospital. A large range of $0,5-5,4 \%$ is given in the literature. We think that intraoperative embolic factors are more frequently involved in the etiology of neurological injury in our patients.

Keywords: central venous catheter, anatomic landmark, ultrasonography, newborn, perioperative complications, coste
Alındığı tarih: 09.10.2018

Kabul tarihi: 05.11.2018

Yayın tarihi: 30.06.2019

Şerife Gökbulut Bektaş Türkiye Yüksek Ihtisas EAH Kızılay Sok. Sihhıye Ankara - Türkiye serifegbektas@gmail.com ORCID: 0000-0001-6057-723X

M. A. Çavuş 0000-0003-2584-0463 A. Demir 0000-0003-3053-0443 Türkiye Yüksek Ihtisas EAH Kızılay Sok. Sihhiye Ankara - Türkiye

(C) Telif hakkı Göğüs Kalp Damar Anestezi ve Yoğun Bakım Derneği'ne aittir. Logos Tıp Yayıncılık tarafindan yayınlanmaktadır. Bu dergide yayınlanan bütün makaleler Creative Commons Atff-Gayri Ticari 4.0 Uluslararası Lisansı ile lisanslanmıştı. 


\section{Giriş}

Nörolojik hasarlanma, kalp cerrahisinin en üzücü komplikasyonlarından biridir. Hastanın kardiyak sorunları çözülse bile serebral olayların ortaya çıkardığı morbidite hem hastanın yaşam kalitesini önemli derecede etkilemekte hem de yüksek maliyetlere neden olmaktadır. Bu dönemde ortaya çıkan nörolojik komplikasyonlar genellikle 2 kategoride incelenmektedir. Tip 1 hasar; inme, geçici iskemik atak, koma ve ensefalopatiyi içerir. Bu hasarlanmalar sıkIıkla klinik ve radyolojik olarak beyin parankiminde belirgin şekilde gözlenebilen lezyonlar nedeniyle meydana gelir. Birçok araştırmada, kalp cerrahisi sonrası inme sıklığı araştırıımış ve \%1.6 ile \%4.6 arasında değişen değerler elde edilmiştir ${ }^{[1-4]}$. Tip 2 hasar ise; konfüzyon, ajitasyon, hafıza bozukluğu, fokal hasar belirtisi olmayan nöbet, nörokognitif disfonksiyon gibi standart klinik ve radyolojik bulgularla tanısı konamayan ve \%50-80 gibi çok daha sık oranda karşımıza çıkan bir klinik durum kompleksidir ${ }^{[5,6]}$.

Bu makalede, yüksek volümlü açık kalp cerrahisi yapılan merkezimizde son 2 yıl içinde postoperatif Tip 1 nörolojik hasar gelişmiş hastaları irdelemeyi amaçladık.

\section{GEREÇ ve YÖNTEM}

Hastanemiz Retrospektif Çalışmalar Etik Kurulu'ndan 41 sayı ve 29.05.2018 tarih numarası ile onay alındıktan sonra, 2016 yılının 2. yarısından, 2018 yılının ilk 6 ayına kadar geçen 2 yıllık süre içinde kardiyopulmoner baypas kullanılarak ameliyat edilmiş 2.689 hasta olduğu görüldü. İnme, geçici iskemik atak, koma ve ensefalopatiyi içeren Tip 1 nörolojik hasarlanma postoperatif ilk 24 saatlik dönemde nöroloji ve radyoloji konsültasyonu ile değerlendirilmiş ve kayıt altına alınmıştır. Konfüzyon, ajitasyon, hafıza bozukluğu, nöbet, nörokognitif disfonksiyon gibi Tip 2 hasarlanma gelişen hastalar ise çalışmamıza dâhil edilmedi. Hasta kayıtlarına göre Tip 1 nörolojik hasar gelişen 50 hastanın verilerine ulaşıldı. Pediyatrik hastalar, off-pump cerrahiler, kalp transplantasyonu ve vasküler cerrahi geçiren hastalar ile önceden serebrovasküler olay öyküsü olan hastalar retrospektif gözlemsel çalışmamıza dâhil edilmedi. Hastane elektronik veri tabanından ve arşivden dosya taraması yapılarak bu hastaların pre-intra ve postoperatif verilerine ulaşıldı. Hastanemizin rutin uygulamalarına göre olgulara anestezi premedikasyonunda 1 gece önce 5-10 mg oral diazepam verilmişti. Ameliyat odasında elektrokardiyografi (EKG), invaziv arteriyel kan basıncı, periferik oksijen satürasyonu, soluk sonu $\mathrm{CO}_{2}$, santral venöz basınç (internal juguler venden), nazofarengeal ve rektal ısılar monitörize edilir. Anestezi indüksiyonunda midazolam (Roche Ltd Basel, Switzerland) $0.1 \mathrm{mg} / \mathrm{kg}^{-1}$, fentanil (Janssen-Cilag, Beerse-Belgium) $5-10 \mathrm{mcg} / \mathrm{kg}^{-1}$, rokuronyum 0.5 $\mathrm{mg} / \mathrm{kg}^{-1}$ (Schering plough), anestezi idamesinde $\% 50 \mathrm{O}_{2}$ /havaya ek olarak 1 MAC sevofluran, midazolam, fentanil ve rokuronyum kullanılır. Kliniğimizde kardiyak re-ameliyat geçirecek hastalara, uzun ve kompleks cerrahilere, aort cerrahisine, 3 damar ve üzeri koroner greftleme ile kapak ameliyatlarına 10 $\mathrm{mg} / \mathrm{kg}$ yükleme ve $1 \mathrm{mg} / \mathrm{kg}$ infüzyon olacak şekilde traneksamik asit uygulaması yapılır. Olgular, aktive pıhtılaşma zamanı (ACT) >450 olacak şekilde heparinize edilir. Kliniğimizde rutin uygulanan bu yönetimlere ilaveten alfa stat kan gazı, orta dereceli hipotermi kullanımı ve kısmi hasta kan yönetimi uygulamaları olgularda standarttı. Serebral monitörizasyon (EEG ve NIRS) rutin olmamakla birlikte, karotis ve aort cerrahisi hastalarında sıklıkla kullanılmaktadır. Araştırdığımız olgularda serebral monitörizasyon az sayıda hastaya yapılmış ve eksik veriler içermekte olduğundan değerlendirilmedi. Kliniğimizde hasta kan yönetimi açısından preoperatif dönemde anestezi tarafından açık anemi belirlenen hastalar hematoloji kliniğine yönlendirilse de birçok anemik hastaya preoperatif dönemde müdahale edilemeden ameliyat yapılmıştı. Cerrahların bu konudaki bilgi ve farkındalık eksikliği, kardiyak hastanın anemi tedavisi için beklemesini uygun görmemeleri nedeni ile preoperatif aşamaya fazla müdahale edilemediği görüldü. İntraoperatif kan kaybını azaltıcı stratejiler açısından yüksek kanama riski olan 
hastalarda ve cerrahi prosedürlerde cell-saver kullanıldı. Yukarda açıklandığı gibi traneksamik asit uygulaması yapıldı. Kardiyopulmoner baypas başlangıcında otolog donasyon amacıyla hasta kanı ayrıldı ve ameliyat sonunda retransfüze edildi. Kardiyopulmoner baypas pompası daha az volümle prime edildi. Intraoperatif dönemde hasta ve koşullara göre bireyselleştirilmekle birlikte, komorbiditesi olmayan hastalarda intraoperatif transfüzyon için eşik hemoglobin değeri $7 \mathrm{~g} / \mathrm{dl}$, komorbiditesi olan hastalarda ise 9-10 g/dl olarak kabul edildi. Demografik bilgilerin yanında preoperatif komorbiditeleri, hemoglobin, glukoz, lökosit ve kreatinin değerleri kaydedildi. Intraoperatif döneme ait cerrahi prosedür, kros klemp ve kardiyopulmoner baypas süreleri, kan ve kan ürünü transfüzyonları, medikasyonları, ultrafiltrasyon ve intraaortik balon pompası kullanımları, en düşük hemoglobin, delta hemoglobin, en yüksek glukoz ve en düşük ısı değerleri kaydedildi.

Delta hemoglobin, giriş hemoglobininden pompadaki en düşük hemoglobin çıkarılarak hesaplanmıştır. Postoperatif dönemde ilk 24 saatte serebral

\section{Tablo 1. Preoperatif demografik veriler.}

\begin{tabular}{|c|c|c|}
\hline Özellik & $\begin{array}{c}\text { Mean } \pm \text { SD } \\
\text { or } n(\%)\end{array}$ & $\begin{array}{c}\text { Median } \\
\text { (IQR) }\end{array}$ \\
\hline Yaş (yıl) & $60.4 \pm 10.2$ & $60(54-69)$ \\
\hline Erkek cinsiyet & $36(\% 72)$ & \\
\hline Hipertansiyon & $30(\% 60)$ & \\
\hline Diabet & $11(\% 22)$ & \\
\hline Periferik arter hastalığı & $1(\% 2)$ & \\
\hline $\mathrm{KOAH}$ & $3(\% 6)$ & \\
\hline Karotid arter hastalığı & $6(\% 12)$ & \\
\hline Hyperlipidemi & $4(\% 8)$ & \\
\hline$<\mathrm{EF} 40$ & $3(\% 6)$ & \\
\hline $\mathrm{EF}(\%)$ & $50,5 \pm 10.9$ & 55 (45-58) \\
\hline Anjiografi zamanı (gün) & $19.6 \pm 13.2$ & $22(6-27)$ \\
\hline MI (3 hafta içinde) & $9(\% 18.4)$ & \\
\hline Acil cerrahi & 7 (\%14.3) & \\
\hline Hemoglobin $\left(\mathrm{g} \mathrm{dl}^{-1}\right)$ & $13.1 \pm 2.4$ & $12,9(11.4-14.2)$ \\
\hline Glukoz (mg dl-1 $\left.{ }^{-1}\right)$ & $117.8 \pm 48.9$ & $116(106-135)$ \\
\hline Beyaz küre sayısı $\left(\times 10^{9} / \mathrm{mm}^{3}\right)$ & $9.7 \pm 3.5$ & $9.2(7.8-10,5)$ \\
\hline Kreatinin $\left(\mathrm{mg} \mathrm{dl}^{-1}\right)$ & $1.01 \pm 0.37$ & $0.92(0.73-1.08)$ \\
\hline
\end{tabular}

KOAH: Kronik obstruktif akciğer hastalığı, EF: Ejeksiyon fraksiyonu, MI: Miyokard infarktüsü hasarlanmanın yanı sıra gelişmiş diğer komplikasyonlar, laboratuvar değerleri, nörolojik hasar etiyolojisi değerlendirildi. Hasar sonrasında kalıcı veya geçici defisit varlığı erken dönemde değerlendirilmiştir, mortalite bilgileri de kaydedilmiştir.

\section{İstatistiksel analiz}

Normal olarak dağıtılan sürekli değişkenler, normal dağılmadığında, ortalama değerıstandart sapma (SD) veya ortanca değer ile en düşük ve en yüksek değer olarak belirtildi. Kategorik değişkenler sayı ve yüzde olarak belirtildi. Tüm istatistiksel analizler SPSS istatistik yazılımı (SPSS for Windows 15.0, Inc., Chicago, IL, ABD) kullanılarak yapıldı.

\section{BULGULAR}

Hastanemizde son 2 yıl içerisinde kardiyopulmoner baypas (KPB) eşliğinde açık kalp cerrahisi geçirdikten sonra açık inme ve serebrovasküler olay (Tip 1 nörolojik hasarlanma) gelişen 50 hasta araştııılı (\%1.9). Hastaların ortalama yaşı $60.4 \pm 10.2$ iken, erkek cinsiyet tüm hastaların $\% 72$ 'sini oluşturuyordu. Hastaların \%61.2'sine hipertansiyon, \%22.4'üne diyabet eşlik ediyordu (Tablo 1). İntraoperatif özellikler Tablo 2'de verildi, buna göre hastalara en sık uygulanan prosedür \%54 koroner baypas cerrahisi oldu. Bunu çoklu cerrahi prosedürler (\%20) ve aort cerrahisi (\%14) olguları izledi. Ortalama KPB süresi $131.1 \pm 58.6 \mathrm{dk}$. idi, KPB sırasında en düşük hemoglobin ve en düşük sıcaklık değerleri ile en yüksek glukoz değerleri Tablo 2'de verildi. Postoperatif komplikasyonlar ile nörolojik hasarlanma bilgileri ise Tablo 3'te görülmektedir. Buna göre, serebrovasküler olay etiyolojisinde $\% 90$ oranında iskemik inme gözlenirken, SVO sonrası kalı$\mathrm{Cl}$ hasar \%56 hastada bulundu. Mortalite ise 17 hastada (\%34) mevcuttu.

\section{TARTIŞMA}

İki yıllık veriler ışığında yapılan bu araştırmada, hastanemizde açık kalp cerrahisi sonrasında Tip 1 nörolojik hasar gelişme oranı \%1.9 bulundu. Literatürde izole koroner baypas olgularında \%0,5 ve \%1.6 gibi 
Table 2. Intraoperatif-postoperatif özellikler.

\begin{tabular}{|c|c|c|}
\hline İntraoperatif özellikler & $\begin{array}{c}\text { Mean } \pm \text { SD } \\
\text { or } n(\%)\end{array}$ & Median (IQR) \\
\hline $\begin{array}{l}\text { Cerrahi tipi } \\
\text { KABG } \\
\text { Kapak } \\
\text { Asendan Aort } \\
\text { LVAD } \\
\text { Çoklu cerrahi prosedür } \\
\text { Kros-klemp süresi (dk.) } \\
\text { KPB süresi (dk.) } \\
\text { Operasyon süresi (dk.) } \\
\text { Eritrosit transfüzyonu (ünite) } \\
\text { Taze donmuş plazma transfüzyonu (ünite) }\end{array}$ & $\begin{array}{c}27(\% 54) \\
4(\% 8) \\
7(\% 14) \\
2(\% 4) \\
10(\% 20) \\
81.7 \pm 35.2 \\
131.1 \pm 58.6 \\
333.8 \pm 75.7 \\
1.16 \pm 1.53 \\
0.53 \pm 1.04\end{array}$ & $\begin{array}{c}73,5(55-103,5) \\
116(92,5-162,5) \\
330(300-375) \\
1(0-1) \\
0(0-1)\end{array}$ \\
\hline $\begin{array}{l}\text { Kullanılan ilaçlar } \\
\text { Insülin } \\
\text { Furosemid } \\
\text { Mannitol } \\
\text { Traneksamik asid } \\
\text { Steroid }\end{array}$ & $\begin{array}{c}15(\% 30) \\
14(\% 28) \\
- \\
14(\% 28) \\
19(\% 38)\end{array}$ & \\
\hline $\begin{array}{l}\text { Ultrafiltrasyon } \\
\text { IABP } \\
\text { İdrar çıkışı (ml) }\end{array}$ & $\begin{array}{c}6(\% 12) \\
4(\% 8) \\
937.8 \pm 416.3\end{array}$ & 900 (750-1000) \\
\hline 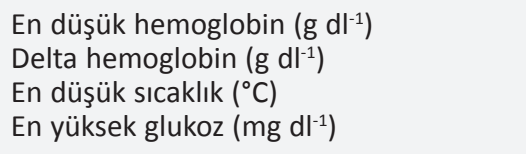 & $\begin{array}{c}7.49 \pm 1.59 \\
4.55 \pm 2.11 \\
30.4 \pm 2.4 \\
187.4 \pm 44.2\end{array}$ & $\begin{array}{c}7.1(6.3-8.2) \\
4.7(3.2-6.1) \\
32(28-32) \\
178(137-227)\end{array}$ \\
\hline \multicolumn{3}{|l|}{ Postoperatif özellikler } \\
\hline $\begin{array}{l}\text { Hemoglobin }\left(\mathrm{g} \mathrm{dl}^{-1}\right) \\
\text { Üre }\left(\mathrm{mg} \mathrm{dl}{ }^{-1}\right) \\
\text { Kreatinine }\left(\mathrm{mg} \mathrm{dl}^{-1}\right) \\
\text { Glukoz }\left(\mathrm{mg} \mathrm{dl}^{-1}\right)\end{array}$ & $\begin{array}{c}8.89 \pm 1.25 \\
57.7 \pm 35.6 \\
1.54 \pm 1.24 \\
184.5 \pm 53.6\end{array}$ & $\begin{array}{c}8.7(8.1-9.6) \\
43(34-61) \\
1.29(0.94-1.62) \\
173(130-215)\end{array}$ \\
\hline
\end{tabular}

Tablo 3. Postoperatif komplikasyonlar ve mortalite.

\begin{tabular}{|c|c|c|}
\hline Özellikler & $\begin{array}{c}\text { Mean } \pm S D \\
\text { or } n(\%)\end{array}$ & $\begin{array}{c}\text { Median } \\
\text { (IQR) }\end{array}$ \\
\hline \multicolumn{3}{|l|}{ Diğer Komplikasyonlar } \\
\hline Yok & $35(\% 70)$ & \\
\hline Enfektif & $4(\% 8)$ & \\
\hline Gastrointestinal & $1(\% 2)$ & \\
\hline Atrial fibrilasyon & $3(\% 6)$ & \\
\hline Kardiyak & 7 (\%14) & \\
\hline Solunumsal & $3(\% 6)$ & \\
\hline Renal & $4(\% 8)$ & \\
\hline \multicolumn{3}{|l|}{ SVO'nun morbiditesi } \\
\hline Yok & $2(\% 4.0)$ & \\
\hline Kalıcı & $28(\% 56)$ & \\
\hline Geçici & $20(\% 40)$ & \\
\hline \multicolumn{3}{|l|}{ SVO'nun etiyolojisi } \\
\hline Kanama & $\begin{array}{c}45(\% 90) \\
0\end{array}$ & \\
\hline Bilinmeyen & $5(\% 10)$ & \\
\hline Mortalite & $17(\% 34)$ & \\
\hline
\end{tabular}

SVO: Serebrovasküler olay

KABG: Koroner arter baypas greftleme, LVAD: Sol ventrikül assist device, KPB: Kardiyopulmoner baypas, IABP: Intraaortik balon pompası

daha düşük oranlar göze çarpmakta iken, bütün açık kalp cerrahisi olgularının dâhil edildiği çalışmalarda \%5.4'e varan daha yüksek sıklıklar ortaya sunulmaktadır ${ }^{(3,4,7-11)}$. Gözlemlerimiz bütün kalp cerrahisi olgularını içermektedir. Olguların yarıdan fazlası koroner cerrahisi olmakla birlikte, çoklu ameliyatlar, kapak ve aort cerrahisi olguları ile sol ventrikül destek cihazı takılan 2 hasta major serebrovasküler olay görülen 50 kişilik grupta yer almaktadır. Bu açıdan bakıldığında, \%1.9 oldukça kabul edilebilir bir orandır. Ancak kardiyak cerrahi sonrasında hedef her zaman daha az komplikasyonla daha kaliteli yaşam sağlama olmalıdır. Bu nedenle en önemli morbidite nedeni olan serebrovasküler hasarlanma nedenleri ayrıntı ile irdelenmektedir. Perioperatif nörolojik hasarlanmaya katkıda bulunan durumlar hasta ile ilişkili faktörler, intraoperatif ve postoperatif faktörler olarak sınıflanır. Hasta ile ilişki faktörlerde 60 yaş üzerinde olmak, kadın cinsiyet, preoperatif kötü sol ventrikül fonksiyonu, kritik preoperatif durum, diyabet, hipertansiyon varlığı, önceden geçirilmiş inme karşımıza çıkmaktadır [11]. Sonuçlarımızda, major nörolojik hasarlanma gözlenen hastaların ortalama yaşları 60.4, kadın cinsiyet oranı ise \%28 olarak bulundu. Hipertansiyon \%60 hastada, diyabet \%22 hastada gözlendi. Düşük ejeksiyon fraksiyonu 3 hastada gözlendi, 9 hastada (\%18) son 3 ay içinde geçirilmiş miyokardial infarktüsü vardı. Bu kötü kardiyak durum 
12 hastayı preoperatif olarak etkilemiş risk faktörleri olarak göze çarptı. Yeni gelişmiş hadiseleri belirleme amacında olduğumuz için önceden serebrovasküler olay geçirmiş hastalar araştırmaya alınmadı. Yaş, cinsiyet veya diğer komorbiditeler gibi hastaya ait faktörler açısından çalışma grubunda herhangi bir risk faktörü yığııması saptanmadı. Hastaların preoperatif hemoglobin değerleri ortalaması $13.1 \mathrm{~g} \mathrm{dl}^{-1}$ idi. Preoperatif anemi varlığı kalp cerrahisi sonrası inme gelişimi için bağımsız bir risk faktörü olarak öne sürülmektedir ${ }^{[12]}$. Hasta grubumuzun çoğunda belirgin anemi bulunmadı. Ameliyat öncesinde hemoglobinin minimum ve maksimum değerleri 11.4-14.2 g $\mathrm{dl}^{-1}$ olarak değerlendirildi. Beş hastada preoperatif hemoglobin değeri $13 \mathrm{~g} \mathrm{dl}^{-1}$ nin altında bulundu, ancak bunlar ciddi anemik değerler değildi.

İntraoperatif risk faktörlerine bakıldığında cerrahi tipine göre aort cerrahisi ve çoklu prosedür olgularında risk daha yüksek sunulmaktadır. Aortik aterom üzerine kros klempleme, KPB sırasında mikroembolizasyon, hipoperfüzyon, Isı ve hematokrit değişkenleri de intraoperatif risk faktörleri arasında değerlendirilmektedir ${ }^{[10,11]}$. Birçok yerde inme önlemi olarak rutin uygulanan epiaortik ultrason dijital palpasyonla belirlenemeyen aterom plaklarını saptamakta ve böylece aort üzerindeki manipülasyonlar kontrollü şekilde yapılmaktadır ${ }^{[13]}$. Hastanemizde rutin epiaortik ultrason uygulanmamaktadır, cerrahların dijital palpasyonu kılavuzluğunda işlemler gerçekleştirilmektedir. Sunduğumuz 50 hastalık bu seride olguların \%90'ında iskemik inme görülmüştür, dolayısıyla etiyolojide embolik olayların rol oynadığı açıktır. Aterom plaklarının yanında diğer mikroemboliler ve hava-lipit embolilerine önlem olarak aksiller arter kanülasyonu, tek klemp tekniği, karbondioksit insuflasyonu gibi yöntemler önerilmektedir ${ }^{[13-16]}$. Rutin uygulamalarımızda bu yöntemler de bulunmamaktadır. Perioperatif dönemde emboli saptama açısından rutin nöromonitörizasyon uygulaması da yapılmadığından, ancak postoperatif dönemdeki serebral tomografi sonuçlarına bakılarak çoğu olguda saptanan iskemik lezyon nedeniyle olayların kaynağının emboli lehine olduğu öngörülmüştür. Hipoperfüzyon özellikle kardiyopulmoner baypas sırasında ortaya çıkan bir diğer inme risk faktörüdür. Olguların $\% 10$ 'unda tomografi sonucunda iskemi veya kanama lehine bulgu saptanmamış, hipoperfüzyonu düşündüren radyolojik ödem ve klinik bulgular gözlenmiştir. Bu nedenle pompa sırasında yüksek perfüzyon basınçları sağlanması da nörolojik hasarı önleme teknikleri arasındadır [17]. Hastalarda, hipertansiyon nedeniyle serebral otoregülasyon eşiklerinin yükselmesi, birçok insana göre normal kabul edilen arteriyel basınç ve perfüzyon değerlerinin yetersiz kalması riskine yol açmaktadır. Bu nedenle normal değerlerde sürdürüldüğü sanılan ameliyatlardan sonra hipoperfüzyona bağlı serebral hasar görülebilmektedir. Pompa sırasında gözlenen en düşük hematokrit/ hemoglobin değerlerinin yani hemodilüsyon derecesinin de postoperative inmeye katkısının olduğu düşünülmektedir ${ }^{[18,19]}$. Buna göre $21^{\prime}$ in altındaki hematokrit değerlerinde inme riski artıyor ve $18 \mathrm{~g}$ $\mathrm{dl}^{-1}{ }^{\prime}$ nin altında bu olasılık 3 kat daha fazlalaşıyor görünmektedir. Hastalarımızda pompada gözlenen en düşük hemoglobin değeri 7,5 $\mathrm{g} \mathrm{dl}^{-1}$ (6.3-8.2) olarak gözlenmiştir, literatürdeki bilgilere göre hastalarımız sınırda seyretmektedir. Intraoperatif kan ve kan ürünü transfüzyon oranları, hastanemizde hasta kan yönetimi kısmi olarak uygulandığından oldukça düşük düzeyde izlenmiştir. Perioperatif glukoz değerlerinin de inme ile ilişkili olduğu bilinmektedir ${ }^{[20]}$. Kliniğimizde diabet tanısı olan hastalara perioperatif insulin tedavisi uygulanmakta, bunun dışında kan şekeri $180 \mathrm{~g}$ $\mathrm{dl}^{-1}$ üzerinde olduğu zaman insülin başlanmaktadır. Buna göre hastaların \%30'una insulin tedavisi gerekli olmuştur. Vücut sıcaklığı yönetimi nörolojik sonuçlar için önemli olan diğer bir konudur. Hipoterminin koruyucu etkileri olduğu iddiasının yanı sıra hipotermi ve normotermi arasında inme riski açısından fark bulamayan çalışmalar da vardır ${ }^{[21]}$. Esas sorunun hipotermi uygulamasından sonra hızlı ısınma nedeniyle serebral hiperterminin olumsuz etkileri olduğu da söylenmektedir [22].

Postoperatif atrial fibrilasyon kardiyak cerrahide \%30'un üzerinde gözlenmektedir ${ }^{[20]}$. Sık gözlenmekle birlikte serebral iskemik olaylarla birlikteliği vurgu- 
lanmaktadır. Serebral iskemik olay gözlenen hastalarda atrial fibrilasyon oranı \%36,5 verilmiştir, ancak hastalarımızda atrial fibrilasyon \%6 olarak bulunmuştur ${ }^{[23]}$. Bunun yanında, ilave kardiyak komplikasyonlar $\% 14$, renal ve enfektif komplikasyonlar ise \%8 olguda gözlenmiş̧ir.

Postoperatif nörolojik hasarlanma gelişen 50 hastanın 2'si sekel kalmadan iyileşmiş, \%40 hastada geçici serebrovasküler olay geri dönmekle birlikte, sekel kalmış, \%56 hastada ise kalıcı ağır sekel varlığı izlenmiştir.

Nörolojik komplikasyonlar morbidite ve mortaliteyi arttıran önemli bir sorundur. Hastalarımızdaki nörolojik hasarlanmanın etiyolojisinde preoperatif özellikler ve komorbiditelerden çok intraoperatif tromboembolik faktörlerin rol oynamış olabileceğini düşünmekteyiz.

\section{KAYNAKLAR}

1. Reich DL, Bodian CA, Krol M, Kuroda M, Osinski T and Thys DM. Intraoperative hemodynamic predictors of mortality, stroke, and myocardial infarction after coronary artery bypass surgery. Anesth Analg. 1999;89:814-22.

2. Hogue CW Jr, Murphy SF, Schechtman KB, and Da' vilaRoma' $n$ VG. Risk factors for early or delayed stroke after cardiac surgery. Circulation. 1999;100:642-7.

3. Almassi GH, Sommers T, Moritz TE, Shroyer AL, London MJ, Henderson WG, et al. Stroke in cardiac surgical patients: Determinants and outcome. Ann Thorac Surg. 1999;68:391-8.

4. Anyanwu AC, Filsoufi F, Salzberg SP, Bronster DJ, Adams $\mathrm{DH}$. Epidemiology of stroke after cardiac surgery in the current era. J Thorac Cardiovasc Surg. 2007;134: 1121-7.

5. Salazar JD, Wityk RJ, Grega MA, Borowicz LM, Doty JR, Petrofski JA, et al. Stroke after cardiac surgery: shortand long-term outcomes. Ann Thorac Surg. 2001;72:1195-201.

6. Gottesman RF, McKhann GM, Hogue CW. Neurological complications of cardiac surgery. Semin Neurol. 2008;28:703-15.

7. Newman MF, Schell RM, Croughwell N, et al. Pattern and time course of cognitive dysfunction following cardiopulmonary bypass. Anesth Analg 1993;76:294.

8. Palmerini T, Savini C, Di Eusanio M. Risks of Stroke After Coronary Artery Bypass Graft - Recent Insights and Perspectives. Interv Cardiol. 2014;9:77-83.

9. Tarakji KG, Sabik JF 3rd, Bhudia SK, Batizy LH, Blackstone $\mathrm{EH}$. Temporal onset, risk factors, and outcomes associ- ated with stroke after coronary artery bypass grafting. JAMA. 2011;305:381-90.

10. Costa MA, Gauer MF, Gomes RZ, Schafranski MD. Risk factors for perioperative ischemic stroke in cardiac surgery. Rev Bras Cir Cardiovasc. 2015;30:365-72.

11. Anyanwu AC, Filsoufi F, Salzberg SP, Bronster DJ, Adams $\mathrm{DH}$. Epidemiology of stroke after cardiac surgery in the current era. J Thorac Cardiovasc Surg. 2007;134: 1121-7.

12. Karkouti K, Wijeysundera DN, Beattie WS. Reducing Bleeding in Cardiac Surgery Investigators. Risk associated with preoperative anemia in cardiac surgery: a multicenter cohort study. Circulation 2008;117:47884.

13. Ingone B, Rauber E, Gatti G, Pappalardo A, Benussi B, Dreas $L$, et al. The impact of epiaortic ultrasonographic scanning on the risk of perioperative stroke. Eur J Cardiothorac Surg. 2006;29:720-8.

14. Hedayati N, Sherwood JT, Schomisch SJ, Carino JL, Markowitz AH. Axillary artery cannulation for cardiopulmonary bypass reduces cerebral microemboli. J Thorac Cardiovasc Surg. 2004;128:386-90.

15. Aranki SF, Sullivan TE, Cohn LH. The effect of the single aortic cross-clamp technique on cardiac and cerebral complications during coronary bypass surgery. J Card Surg. 1995;10:498-502.

16. Svenarud $\mathrm{P}$, Persson $\mathrm{M}$, van der Linden J. Effect of $\mathrm{CO}_{2}$ insufflation on the number and behavior of air microemboli in open-heart surgery: a randomized clinical trial. Circulation. 2004;109:1127-32.

17. Gold JP, Charlson ME, Williams-Russo P, Szatrowski TP, Peterson JC, Pirraglia PA, et al. Improvement of outcomes after coronary artery bypass. A randomized trial comparing intraoperative high versus low mean arterial pressure. J Thorac Cardiovasc Surg. 1995;110:130211.

18. Karkouti K, Djaiani G, Borger MA, Beattie WS, Fedorko $L$, Wijeysundera $D$, et al. Low hematocrit during cardiopulmonary bypass is associated with increased risk of perioperative stroke in cardiac surgery. Ann Thorac Surg. 2005;80:1381-7.

19. Loor G, Koch CG, Sabik JF 3rd, Li L, Blackstone EH. Implications and management of anemia in cardiac surgery: current state of knowledge. J Thorac Cardiovasc Surg. 2012;144:538-46.

20. Hogue CW, Gottesman RF, Stearns J. Mechanisms of cerebral injury from cardiac surgery. Crit Care Clin. 2008;24:83-98.

21. Rees K, Beranek-Stanley M, Burke M, Ebrahim S. Hypothermia to reduce neurological damage following coronary artery bypass surgery. Cochrane Database Syst Rev. 2001;1:CD002138.

22. Cook DJ, Orszulak TA, Daly RC, Buda DA. Cerebral hyperthermia during cardiopulmonary bypass in adults. J Thorac Cardiovasc Surg. 1996;111:268-9.

23. Lahtinen J, Biancari F, Salmela E, Mosorin M, Satta J, Rainio $P$, et al. Postoperative atrial fibrillation is a major cause of stroke after on-pump coronary artery bypass surgery. Ann Thorac Surg. 2004;77:1241-4. 